\title{
Peter G. Brown and Jeremy J. Smith (eds): Water Ethics: Foundational Readings for Students and Professionals
}

\author{
Island Press, Washington, Covelo, London, ISBN: 978-1-59726- \\ 564-5 (cloth.)/ISBN 978-1-59726-565-2 (pbk.)
}

\section{Neelke Doorn}

Accepted: 16 March 2011/Published online: 9 April 2011

(C) The Author(s) 2011. This article is published with open access at Springerlink.com

\begin{abstract}
"Water is essential for life." This opening sentence of the recently published text book on water ethics will probably not raise any eyebrows. Despite the fact that we all seem to recognize the importance of water, it has so far been neglected as an independent topic for ethical reflection; there is no systematic account of how to value water. Sure, water is discussed as a topic related to climate ethics or as a renewable resource. However, it is increasingly recognized that water is more complex than that. In water management circles, it is by now recognized that water (and its scarcity) is likely to be one of the most pressing global problems that we will be faced with in the coming years. At the same time, climate change also poses challenges related to flooding; that is, situations where there is a "surplus" of water. The North Sea countries in Europe, for example, are faced with a challenge to deal with both coastal attacks (due to global sea rise) and increasing river discharges. At the same time, almost every summer in the last decade, these same European countries faced a period of water shortage. This superficial example already shows the importance of water and its complexity. To put it in simple terms: water raises distribution issues, be it the distribution of (flood) risks or the distribution of scarce resources.
\end{abstract}

Peter G. Brown and Jeremy J. Smith have taken upon themselves the challenge of putting ethics on the agenda of water experts (be it professionals or students). The volume stands in the tradition of integrated water management, where a comprehensive view on water management is developed covering different water uses. In a very readable introduction, the editors describe water ethic (singular!) as "deal[ing] with problems that arise in disagreements regarding what ought to be done." Subsequently, they mention three areas where these problems may arise: claims about facts or states of affairs, more specifically, about "adequate" water

\footnotetext{
N. Doorn $(\bowtie)$

Department of Technology Policy and Management, Section of Philosophy, 3TU. Centre of Ethics and Technology/Delft University of Technology, PO Box 5015, 2600 GA Delft, The Netherlands e-mail: N.Doorn@tudelft.nl
} 
quantity of quality; claims about correctly ordered social relationships, such as on the basis of what rationale water should be allocated; and claims about personal experiences, such as water's significance to people of a particular culture or belief. In the remainder of this chapter, the editors set out the relationship between water management and ethics, followed by a discussion of the outline of the book. Although this definition of "water ethic" leaves open the possibility of including problems with flooding as well, the sole focus in the book is on water as a scarce resource.

Apart from the introduction, the book is divided into five parts, each preceded by an editors' introduction. The first one deals with a discussion of the various human claims to water and the different religious and legal systems that support these claims. The second part deals with utilitarianism, being the dominant principle in resource policy. In the third part, the most developed alternative to utilitarianism is presented: water as a community resource. Most authors in this part take Garret Hardin's Tragedy of the commons (Hardin 1968) as a starting point for developing their own account of water scarcity. In the remaining two parts, water is discussed in the wider context of life's common wealth, including all living things, and ethics as part of a complex system. In these latter parts, Aldo Leopold (Leopold 1966), not surprisingly, proves to be the major source of inspiration.

This organization of the book already reveals two important points. First, the way we conceive of water also determines how we (ought to) approach distributive issues pertaining to water. If water is to be used at humanity's discretion, a view often linked to the Judeo-Christian tradition, water almost automatically gets instrumental value. If water is considered a commodity (like, for example, electricity or oil), water's monetary price will probably become more important. Secondly, water-both if considered in terms of scarcity or as risk-cannot be seen apart from the institutional context. How should decision making be organized, institutionally, such that water is distributed in a fair or just way? The editors convincingly argue that these questions are closely related: we cannot decide on how to structure the water market without taking into account the broader worldviews regarding the earth, its water, and the place of humanity within it.

The editors present the field of water ethics as relatively new and it is therefore not surprising that they were not able to provide a systematic account of the field. All contributions are reprints, some going back as far as the 1980s, and almost half of them do not deal specifically with water but more with eco-ethics in general. The quality of the different contributions is therefore highly varying, both in terms of relevance for water ethics and in terms of depth (the length of the papers, for example, vary between 4 and 21 pages). Some papers are outstanding. The paper written by Nobel laureate Elinor Ostrom and colleagues, although to a large extent going back to her older work in the early 1990s (Ostrom 1990), is still one of the most convincing accounts of water as a common-pool resource. In a clarifying way, the authors discuss the lessons learnt in common-pool resource theory and relate these to questions of institutional and governance design. They emphasize the importance of taking into account the particularities of the situation. It is not possible to provide a blueprint or set of design principles for successful resource 
management; the particularities of the situation will always have to be taken into account to decide what is appropriate.

In a way, this lesson is taken seriously by the editors themselves. They alternate theoretical contributions with case studies. These case studies cover a large geographical area, ranging from Arab regions to individual countries such as Canada, China, Kenya, Nepal, Peru, Spain, and the United States.

The complexity of water, as an object of ethical reflection, poses the problem of audience. The ethics of water (or maybe, of water governance) is a topic that is unavoidably multidisciplinary. Although one need not be a full-fledged hydrologist, at least some familiarity with water is required. Similarly, seeing the full potential of the case studies requires a familiarity with qualitative studies, preferably with anthropological economy or policy science. On a whole, it seems that especially the ethical reflection is relatively underdeveloped. From an applied philosophical point of view, it would be interesting to discuss water ethics in the light of Thomas Pogge's view on human rights and institutional design (Pogge 2008) or Sen and Nussbaum's capability approach (Sen 1985, 1999; Nussbaum 2000). The discussion of rights and distributive issues seems to stop at a point where these conceptual issues become particularly pressing.

It is hard to compile a set of contributions that proves readable for an audience of such varying nature, especially if the field has not fully matured yet. The book suggests that there is quite some qualitative material available of successful and unsuccessful community-based projects, also ones with conflicting water demands. What seems to be lacking, though, is a thorough account of the distributive issues, including geographical and intergenerational ones. In its current form, the book presents an invitation for applied philosophers (be it social, political, or moral philosophers) to join social scientists in developing an ethics of water governance. For ethicists, it is the challenge to go beyond traditional environmental ethics and to develop an ethics that does justice to the particularities of water. This book sets a modest first step for exploring this new terrain.

Open Access This article is distributed under the terms of the Creative Commons Attribution Noncommercial License, which permits any noncommercial use, distribution, and reproduction in any medium, provided the original author(s) and source are credited.

\section{References}

Hardin, G. (1968). The tragedy of the commons. Science, 162(3859), 1243-1248.

Leopold, A. (1966). A Sand County Almanac: With essays on conservation from round river. New York: Oxford University Press.

Nussbaum, M. C. (2000). Women and human development: The capabilities approach. Cambridge: Cambridge University Press.

Ostrom, E. (1990). Governing the commons: The evolution of institutions of collective action. New York: Cambridge University Press.

Pogge, T. W. M. (2008). World poverty and human rights: Cosmopolitan responsibilities and reforms (2nd ed.). Cambridge: Polity Press.

Sen, A. K. (1985). Commodities and capabilities. Amsterdam: Elsevier.

Sen, A. K. (1999). Development as freedom. New York: Anchor Books. 